\title{
Development of a First-Year Engineering Course Classification Scheme
}

\section{Dr. Kenneth Reid, Ohio Northern University}

Ken Reid is the Director of First-Year Engineering, Director of Engineering Education and an Associate Professor in Electrical and Computer Engineering and Computer Science at Ohio Northern University. He was the seventh person in the U.S. to receive a Ph.D. in Engineering Education from Purdue University. $\mathrm{He}$ is active in engineering within K-12, serving on the TSA Boards of Directors and over 10 years on the IEEE-USA Precollege Education Committee. He was named the Herbert F. Alter Chair of Engineering in 2010. His research interests include success in first-year engineering, introducing entrepreneurship into engineering, international service and engineering in K-12.

\section{Mr. Tyler J Hertenstein, Ohio Northern University}

Tyler is a sophomore studying engineering education at Ohio Northern University, where he currently resides as president and co-founder of a student chapter of ASEE. Previously, Tyler has co-authored two papers for the 2012 ASEE North-Central conference. At ONU, tyler is also involved in the Dean's advisory team, Alpha Lambda Delta, Phi Eta Sigma, the yearly STEM day, and Northern Engineers without Boundaries.

\section{Mr. Graham Talmadge Fennell, Ohio Northern University \\ Elizabeth Marie Spingola}

lizabeth is a Junior at Ohio Northern University. She is the Project Manager of an organization at school that is designing and fabricating a model Mars Rover for a local museum. She is, also, has leadership roles in Phi Sigma Rho, the engineering sorority as ONU. Other organizations she belongs to include: SWE, ASME, Flute Choir, JEC and more.

\section{Mr. David Reeping, Ohio Northern University}




\section{Development of a First-Year Engineering Course Classification Scheme}

\section{Introduction:}

A proliferation of first-year engineering programs exists nationwide. These are often designed from scratch and tend to be "personal courses" - designed by instructors to cover what they feel is important. Therefore, while they may be prerequisites to second-year courses, first-year engineering programs are not necessarily integrated into the curriculum. Further, since they are often designed with little consideration for existing models, overall outcomes and content vary widely. This leads to, first, the issue of course developers "reinventing the wheel" as successful models are not adequately disseminated. The problem is exacerbated by a lack of definition of first year models: a developer may know what they want in a course, but how do they find a course with similar outcomes with nothing more than "first-year engineering" as a description?

Second, with little focus on specification of models for these courses, many courses become a grab bag of unrelated topics. The course meant to introduce engineering to a student may instead dissuade them from continuing as they try to understand what engineering is.

This paper will present intermediate results of an NSF sponsored project to define a classification scheme for first-year engineering courses with associated outcomes. For example, courses may include engineering design, engineering analysis, professional skills, or orientation to specific disciplines described by a classification system based on course outcomes ${ }^{1}$.

Results are presented from a multifaceted approach. Approximately 30 syllabi for First-Year or Introduction to Engineering courses have been examined to identify course / learning objectives and any data on assessment methods, and these objectives grouped to establish a framework toward an initial classification scheme. An informal workshop was held at a national conference to build consensus among interested parties; results from this workshop are being used to inform a concurrent Delphi study as it progresses from the initial round to one where the classification scheme is identified and finalized. Multiple rounds of survey data will be collected and analyzed to build a similar classification scheme via the Delphi study.

After establishing the classification schemes, a culminating workshop will be held in which participants identify assessment methods and gaps in those methods in assessing each component of these introduction courses.

Specific goals include (1) categorize and define a classification scheme for first-year courses, including expected outcomes and assessment methods and (2) identify the assessment gaps.

This paper will present current results of the study as the Delphi study begins, including results of the analysis of syllabi and initial results from the informal workshop. These results will serve to establish the framework informing an initial classification scheme and identification of assessment methods and potential assessment gaps. 


\section{Methodology:}

The first step in identifying common concepts, student learning objectives and assessment methodologies was a search of university websites for courses entitled "Introduction to Engineering", "Engineering 1", or courses with similar titles. When such a course was identified, a further search for the course syllabus was completed. A team of undergraduate research assistants was tasked with executing this internet search and summarizing results in cooperation with the principle investigator during the spring semester 2012. Each syllabus found was reviewed to ensure that the course was meant to apply as a common engineering course rather than a technically oriented, discipline specific course: for example, delineating between "Introduction to Engineering" and "Introduction to Electrical Engineering”. Further, courses were not to be general orientation courses geared toward understanding the culture of a university or a general introduction to university life - although these topics may appear in a course meant to introduce engineering. Finally, courses were not to be those that might introduce engineering to non-engineering majors. The intent of this search was to establish a theoretical framework which would guide the upcoming Delphi study.

A workshop for informal discussion of establishing the classification scheme occurred at the Frontiers in Education conference in Seattle, WA in October 2012. A Catalyzing Collaborative Conversations session was proposed and scheduled, organized jointly by Directors of First Year Engineering programs at Ohio Northern University and Virginia Tech. The session offered an opportunity to gather a community with a common interest in first-year engineering education, and have a discussion to independently develop a theoretical framework. Approximately 24 attendees were seated in groups of 6; each group was tasked with having a discussion around a set of guiding questions distributed at the beginning of the workshop. Each group was to have a recorder to capture the results. The initial intent was to allow a time for small group discussion, then to bring the groups together and have a discussion among the full group; however, the conversation was tremendously productive and, rather than interrupt the flow of conversation, the leaders opted to allow the conversations to conclude naturally, or to continue to (and past) the scheduled end of the session.

The guiding questions for each group included:

- What are the objectives of the first-year engineering programs?

- Why isn't there a common set of objectives for the first year engineering courses?

- What would we consider to be the best practices for first year engineering program? For example, should we teach Matlab/Excel rather that introducing students to the disciplines?

- If students were so successful in High School, why is there so much emphasis on success? What do we mean by success? 
- Are there any of these objectives that are hard to assess? How might we assess them? Is there anything that we think should be a best practice that isn't because it is too difficult to assess?

Results from the recorder of each group were summarized, and results of each of these activities were used to develop the initial round of questions for the Delphi study.

The Delphi procedure will be employed to invite a large group of participants with a common interest to develop shared images based on three (or more) rounds of question development and information, with iterative feedback ${ }^{2,3,4,5}$. Approximately 20-30 participants are expected to participate through the entirety of the procedure. Questions for the initial round consist of those developed by a steering committee and refined from results of the first two phases of the project. The second round includes statements gathered and categorized from the responses to the questionnaires. Participants will be asked to respond by ranking, sorting and specifying preferences to the statements, coming to consensus on characteristics used to classify courses, outcomes, assessments, etc., without direct influence found in a group setting.

In the third round, participants will receive final proposed lists of characteristics of each aspect of first year courses, and asked to comment. In the event that consensus is not reached, if issues remain unresolved or if new issues emerge, further rounds may follow, or issues may be resolved through other means.

The Delphi procedure is administered online. The initial invitations to participate came from a list generated by the steering committee, e-mail invitations to listserves for ASEE divisions with interest including the First-Year Programs Division, invitations to participants in the 2012 FirstYear Engineering Experiences conference, and targeted e-mail requests sent to a variety of universities with first-year engineering programs identified through ASEE and through recent literature.

Results of all three methods will be used to define the classification scheme which is planned for presentation and discussion at a culminating workshop during the 2013 First-Year Engineering Experience conference.

\section{Results:}

Analysis of syllabi:

A total of 28 syllabi were found online that met the specific criteria. A diverse set of institutions were represented: community colleges, private and public universities, and large research-based institutions. Each of the syllabi were inspected to pull student learning objectives and/or course objectives, whether they were expressly listed or found in a descriptive summary of the course objectives.

The unofficial classification of the course objectives from the syllabi is shown in figure 1 . Objectives were found to group into four main categories: engineering skills, professional skills, orientation to the university / course / program and orientation to the profession. It is important 
to note that there is often not a clear delineation of objectives: for example, "prepare the student as a person including preparation toward their chosen field" may best fit under orientation to the programs of the university or toward the profession. The analysis of the syllabi is intended to support the Delphi study, so further, specific classification of each objective is considered a work in progress.

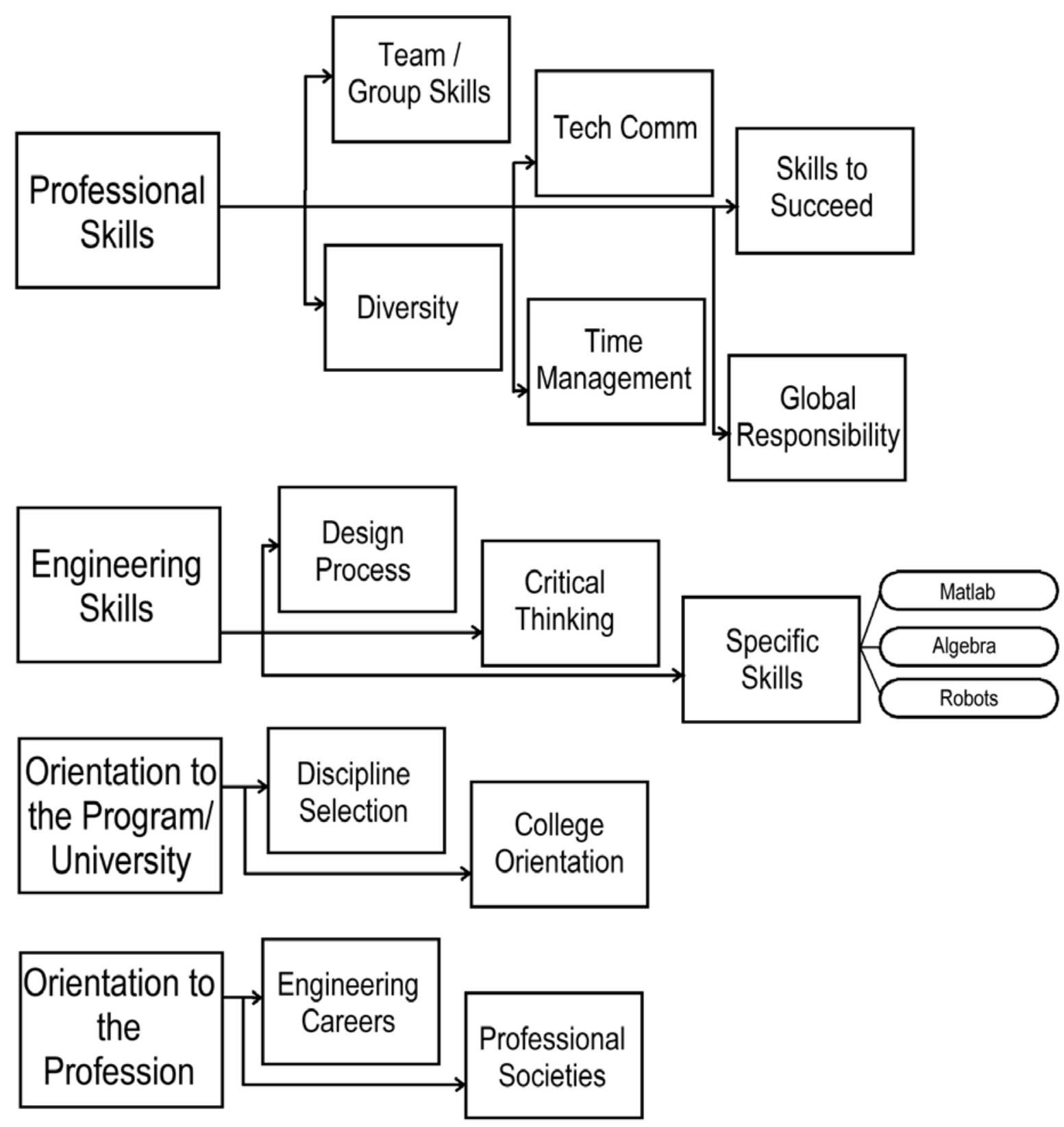

Figure 1: Approximate classification of objectives based on analysis of course syllabi

Individual items under each category are presented based on the frequency they appeared in course syllabi. For example, objectives indicating team or group work appeared most often, followed by technical communication and so on. Objectives mentioned only once were either grouped with similar objectives or classified as 'other' and not included in this initial pass. An 
exception was made for individual specific engineering / technical skills mentioned, such as MATLAB programming.

Analysis of results of workshop discussion:

Similar analysis was done based on the answers to the initial question in the Catalyzing Collaborative Conversations (CCC): "What are the objectives of the first-year engineering programs?" This question generated most of the conversation, and most comments were listed under this item in the notes from each reporter.

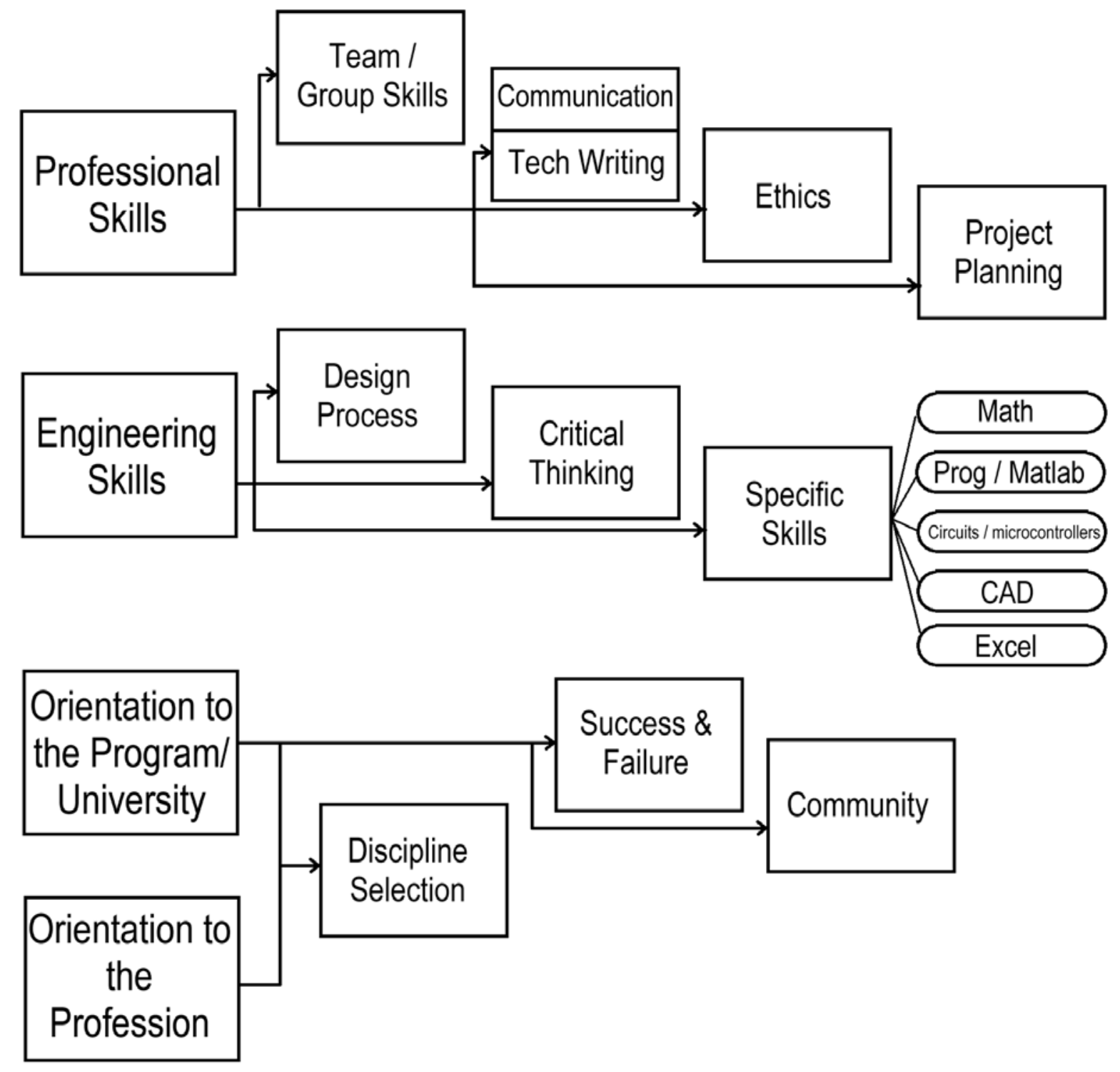

Figure 2: Classification based on CCC workshop

In fact, discussion on the other questions often either 1) drifted back to this point or 2) became a discussion of objectives that should be (but may not currently be) included. Further discussion critiqued the questions themselves. For example, "Are there any of these objectives that are hard 
to assess? How might we assess them?” was discussed. The consensus was objectives that should be included but were not were such because of a lack of time or a lack of defining how to include those objectives rather than their ability to be assessed. This discussion will serve to further inform later rounds of the Delphi study.

Figure 2 shows the draft classification of objectives mentioned in response to the initial question. Four major themes were identified, identical to those from the analysis of the syllabi. Again, any objective mentioned more than one time is included, and items are presented from most often mentioned to most seldom mentioned (but mentioned multiple times). Also, individual engineering skills mentioned are listed for the sake of comparison.

\section{Discussion:}

The same main categories emerged from both analyses. There are key differences beneath each of these categories.

\section{Engineering Skills:}

Specifics under engineering skills showed the least difference between the two activities. The only difference was in specific engineering skills listed, which could have come from 1) not listing specific engineering skills on course syllabi and 2) the dynamics of a group discussion. If similar results appear after round 1 of the Delphi study, further rounds will offer more clarity.

\section{Professional Skills:}

Teaming skills and communication were by far mentioned in most if not all syllabi and group discussion. Given that these are often the most cited characteristics from employers and specifically cited in ABET criteria, this is not surprising.

From here, the most often cited objectives in the CCC workshop were a consideration of engineering ethics and project planning, which did not appear in the analysis of syllabi. It is possible - and remains to be investigated - whether, for example, "project planning" and "time management” are meant to be included in the same category. The lack of 'ethics' appearance in course syllabi is somewhat surprising.

The difference in a single 'communication' block vs. a block where technical writing is separated may not be significant. Investigation and discussion on the individual elements of technical communication remain.

\section{Orientation:}

Analysis of syllabi seemed to indicate that a selection of disciplines was more related to orientation to the engineering program in general. The discussion seemed to go in two distinct directions: orientation to the university's engineering program and to the profession. The difficulty in determining the intended meaning of objectives from course syllabi means that this 
distinction is also a work in progress, and the Delphi study results and culminating discussion should shed light on whether this should fall into either category or a category on its own.

Another interesting objective that emerged from the CCC discussion was success and failure. Indeed, there are multiple efforts to incorporate a true appreciation of failure into engineering plans of study; but this only appeared as a course objective in one syllabus. Further investigation is necessary.

\section{Delphi Study:}

The initial round of the Delphi study is in progress at the time of this paper. The open ended questions and instructions posed to the participants include:

When answering the following questions, please answer them within the framework of Introduction to Engineering / First-Year Engineering course(s). Do not consider other required courses within the first year.

For example, please do not consider math, science or general education courses.

There are no right or wrong answers, and no specific number of items you must include. Please be as complete and descriptive as necessary to fully answer each question.

- What topics are included (please list) in first-year engineering courses at your institution?

- Are there topics that are not, but should be included in first-year engineering courses at your institution? Please list:

(please do not duplicate answers from the previous question)

- What are (please list) the expected student outcomes in first-year engineering courses at your institution?

- What other student outcomes should be included in first-year engineering courses?

Please list:

(please do not duplicate answers from the previous question)

Once completed, the results of the Delphi study will be taken with each analysis described above to form a complete classification scheme. From this scheme, a study of assessment methodologies is expected.

\section{Conclusion:}

Results thus far seem to indicate that course objectives for courses such as "Introduction to Engineering” can be grouped into four major categories: engineering skills, professional skills, orientation to the program from the viewpoint of the university and orientation to the engineering 
profession. There has been some disagreement of specific categories beneath these major headings. The Delphi study and culminating workshop should shed light on the differences and solidify a classification scheme for these courses.

\section{Acknowledgment:}

The authors would like to acknowledge the support provided by the U.S. National Science Foundation (Award DUE-1042030). Any opinions, findings, conclusions, and/or recommendations are those of the investigators and do not necessarily reflect the views of the National Science Foundation.

\section{References:}

[1] Magee, C.L. and O.L. deWeck, 2004. “Complex System Classification”, proceedings of the Fourteenth Annual International Symposium of the International Council On Systems Engineering, Toulouse, France.

[2] Passig, D., 2004. "Variations to the Imen-Delphi procedure aimed at helping in the emergence of communities of interest”, Intellect, 1 (2-3), 95 - 109.

[3] Passig, D., 1997. “Imen-Delphi: A Delphi variant procedure for emergence”, Human Organization, 56 (1), pp. $53-63$.

[4] Linstone, H. A. and M. Turoff, 1975. “The Delphi Method: Techniques and applications”, Addison Wesley.

[5] Hsu, C. and B. Sandford, 2007. "The Delphi Technique: Making Sense Of Consensus”, Practical Assessment, Research and Evaluation, 12 (10), pp. 1-8. 